\title{
Management of menopause-associated vasomotor symptoms: Current treatment options, challenges and future directions
}

This article was published in the following Dove Press journal:

International Journal of Women's Health

7 May 2010

Number of times this article has been viewed

\author{
Deirdre R Pachman' \\ Jason M Jones' \\ Charles L Loprinzi ${ }^{2}$ \\ 'Internal Medicine, Mayo Clinic, \\ Rochester, MN, USA; ${ }^{2}$ Medical \\ Oncology, Mayo Clinic, Rochester, \\ MN, USA
}

\begin{abstract}
Hot flashes are one of the most common and distressing symptoms associated with menopause, occurring in more than $75 \%$ of postmenopausal women. They are especially problematic in breast cancer patients since some breast cancer therapies can induce hot flashes. For mild hot flashes, it is proposed that behavioral modifications are the first step in management. Hormonal therapies, including estrogens and progestogens, are the most well known effective agents in relieving hot flashes; however, the safety of these agents is controversial. There is an increasing amount of literature on nonhormonal agents for the treatment of hot flashes. The most promising data regard newer antidepressant agents such as venlafaxine, which reduces hot flashes by about $60 \%$. Gabapentin is another nonhormonal agent that is effective in reducing hot flashes. While many complimentary therapies, including phytoestrogens, black cohosh, and dehydroepiandrosterone, have been explored for the treatment of hot flashes; none can be recommended at this time. Furthermore, there is a lack of strong evidence to support exercise, yoga, or relaxation for the treatment of hot flashes. Paced respirations and hypnosis appear to be promising enough to warrant further investigation. Another promising nonpharmacological therapy, currently under investigation, involves a stellate ganglion block.
\end{abstract}

Keywords: vasomotor symptoms, hot flashes, menopause, therapy

\section{Introduction}

Menopause, an expected event in a woman's life, is commonly defined as 12 months of amenorrhea. This transition often begins in the late 40 s, with a median age of 51 years. ${ }^{1}$ Menopause is associated with multiple symptoms including vasomotor symptoms, vaginal symptoms, urinary incontinence, sexual dysfunction, and trouble sleeping.

One of the most common and distressing symptoms of menopause are hot flashes. Hot flashes occur in over $75 \%$ of menopausal women. ${ }^{2,3}$ Women often describe these episodes as recurrent periods of flushing, sweating, and an intense heat that begins on the face and upper chest. Hot flashes can also be associated with a feeling of anxiety, palpitations, and red blotching of the skin. . $^{3,4}$ These episodes usually last for 2-4 minutes and can vary in frequency, with some women experiencing episodes multiple times per day, while others experience them as infrequently as once a month. Although not life-threatening, hot flashes can have a detrimental effect on a woman's functional ability and quality of life..$^{5}$

Hot flashes are especially problematic in breast cancer patients. Multiple preventative and treatment strategies for breast cancer can induce hot flashes, including anti-estrogenic medications, oophorectomy, and certain forms of chemotherapy. ${ }^{6,7}$ In addition, it has been reported that breast cancer survivors have more frequent and severe hot flashes than women who undergo normal menopause. ${ }^{8}$
Correspondence: Charles L Loprinzi Mayo Clinic, 200 First Street SW, Rochester, MN 55905, USA

Tel +l 5072844849

Fax +| 507284 I803

Email cloprinzi@mayo.edu 
The purpose of this article is to review the evidence for and against the current available treatments for hot flashes.

\section{Etiology}

The mechanism behind hot flashes is not completely understood. It has long been believed that hot flashes result from the decrease in estrogen levels associated with menopause. During menopause, the number of ovarian follicles and the production of estrogen decreases. Hot flashes seem to occur synchronously with these changes. ${ }^{9}$ However, the exact role of estrogens in the mechanism of hot flashes is unclear. There is research to support the hypothesis that it is the estrogen withdrawal, not low levels of estrogen that leads to hot flashes. For example, women with gonadal dysgenesis, who have consistently low levels of estrogen, do not experience hot flashes unless they are given estrogen replacement therapy, which is later discontinued. Also, women who experience abrupt estrogen withdrawal, such as from oophorectomy, have a rapid onset of hot flashes. ${ }^{10,11}$ In addition, hot flashes are often more prevalent at the beginning of menopause and do not usually continue throughout the postmenopausal time when circulating estrogens are low. ${ }^{11}$

The perspiration and vasodilatation associated with hot flashes appears to be controlled by the thermoregulatory nucleus, which is located in the preoptic area of the hypothalamus. The thermoregulatory nucleus regulates core body temperature and works to keep it within a homeostatic range called the thermoregulatory zone. ${ }^{10}$ Hot flashes are triggered if body temperatures are elevated or sweating thresholds are lowered. ${ }^{12}$ Women who suffer from hot flashes appear to have a thermoregulatory zone that is narrower and thus small increases in core body temperature can trigger hot flashes. ${ }^{13}$

Norepinephrine and serotonin may be involved in the complex neuroendocrine pathway controlling the thermoregulatory zone. ${ }^{9}$ It is proposed that elevated brain norepinephrine narrows the thermoregulatory zone. ${ }^{12}$ In addition, there has been increased interest in the role of serotonin in the hot flash mechanism. Activation of specific serotonin receptors can cause hypothermia or hyperthermia. ${ }^{14}$ Estrogen withdrawal is associated with decreasing levels of serotonin and an increase in serotonin receptors in the hypothalamus. ${ }^{9,11}$ In one proposed model for the pathogenesis of hot flashes estrogen withdrawal leads to a decrease in endorphin and catecholestrogen levels. This in turn leads to increased norepinephrine and serotonin release, which lowers the set point in the thermoregulatory nucleus, thus increasing the likelihood of hot flashes. ${ }^{9}$

\section{Treatment of hot flashes Hormonal therapies Estrogen replacement}

Estrogen replacement is the most effective treatment for reducing hot flashes, with reductions of more than $75 \%$ in frequency. ${ }^{15-17}$ Unfortunately, there are many situations in which estrogen therapy is contraindicated. The Women's Health Initiative (WHI) trial reported that the overall health risks of long-term estrogen therapy; including increased risk of venothrombotic disease, breast cancer, stroke, and coronary artery disease, exceed the benefits. ${ }^{18}$ However, hormone therapy is still approved for the treatment of moderate to severe vasomotor symptoms. ${ }^{17}$ When hormonal treatment is utilized for treating hot flashes, it is generally accepted that it should be used at the lowest dose and for the shortest effective length of time. ${ }^{17,19}$

More recent literature has investigated short-term and low dose estrogens for the treatment of vasomotor symptoms. A double-blind, placebo-controlled trial was undertaken to investigate the efficacy of micro-dose transdermal estrogen for relief of hot flashes. Women used transdermal patches with low dose estrogen $(0.023 \mathrm{mg} / \mathrm{d} 17 \beta$-estradiol and $0.0075 \mathrm{mg} /$ day levonorgestrel), micro-dose estrogen $(0.014 \mathrm{mg} /$ day $17 \beta$-estradiol) or placebo. Women using the micro-dose estrogen had a significant reduction in hot flashes when compared to placebo with $41 \%$ of patients having a reduction in hot flashes of $75 \%$ or more. ${ }^{20}$ Another study evaluated the efficacy of low dose estradiol gel for the treatment of hot flashes. Women received estradiol gel $0.1 \%$ at doses of $1.0,0.5$, and $0.25 \mathrm{mg} / \mathrm{day}$. All three doses demonstrated a statistically significant reduction in the frequency of hot flashes, but these reductions were dose dependent. ${ }^{21}$ Currently, $0.0125 \mathrm{mg} /$ day dose of Elestrin is the lowest effective dose of estradiol gel approved for the treatment of hot flashes. ${ }^{22}$ Studies have shown that low dose estrogen may be less likely to cause many of the serious complications associated with higher dose estrogen. ${ }^{19,20}$ However, the risks associated with long-term use of low dose estrogens are still unknown since this has not been evaluated in clinical trials..$^{19,22}$

The use of estrogen therapy in breast cancer survivors is also a controversial topic. While some literature suggests that estrogen therapy might be safe in breast cancer survivors, ${ }^{6}$ the current sentiment of most clinicans is to avoid the use of estrogen in this population. ${ }^{17,23}$

\section{Progestational agents}

The North American Menopause Society determined that the primary menopausal-related indication for progesterone use is 
to negate the increased risk of endometrial cancer from systemic estrogen therapy. Therefore, the recommendation is that all women with an intact uterus requiring hormonal therapy for menopausal symptoms should be prescribed progesterone. ${ }^{17,24}$ However, in recent years, there have been several trials that have shown progestational agents to be a reasonable alternative to estrogen, for the treatment of vasomotor symptoms.

Megestrol acetate was found to be effective in reducing hot flashes in a double-blind, placebo-controlled, randomized clinical trial that included 97 women with a history of breast cancer and 66 men receiving androgen deprivation therapy for prostate cancer. Patients receiving megestrol acetate, at a dose of $40 \mathrm{mg}$ per day, showed an $85 \%$ reduction in hot flashes, as compared to a $21 \%$ reduction in the placebo group. ${ }^{25}$ A substantial proportion of patients in this trial continued to use megestrol acetate for periods of up to 3 years or longer, with continued control of hot flashes. ${ }^{26}$ In addition, a daily megestrol acetate dose of $20 \mathrm{mg}$ appears to be equally efficacious to a $40 \mathrm{mg}$ daily dose. ${ }^{27}$

Medroxyprogesterone acetate (MPA), a similar medication, comes in both oral and intramuscular forms, both of which have been shown to decrease menopause related hot flashes. Multiple, double-blind, placebo-controlled trials, performed in the 1970 s and 1980 s, found intramuscular depomedroxyprogesterone acetate (DMPA) to be efficacious in reducing hot flashes. ${ }^{28-30}$ A more recent randomized, placebo-controlled clinical trial was undertaken to compare DMPA with megestrol acetate in postmenopausal women with a history of breast cancer; they found both agents to have similar efficacy with a reduction of $86 \%$, on average, in both groups. ${ }^{31}$ In addition, an observational study of 15 women with a history of breast cancer reported that hot flashes were reduced by $90 \%$ in women receiving DMPA. ${ }^{32}$ Another randomized controlled trial demonstrated that DMPA and conjugated equine estrogen were equivalent in their efficacy at reducing hot flashes in patients who underwent hysterectomy/ovariectomy. ${ }^{33}$

The role of progesterone cream for the treatment of hot flashes is controversial. One randomized placebo-controlled trial of a progesterone cream in healthy postmenopausal women found a significant reduction in hot flashes, $83 \%$ compared to $19 \%$ in the placebo group. ${ }^{34}$ However, a recent double-blind, placebo-controlled trial of progestelle progesterone cream in 223 healthy postmenopausal women found no statistically significant difference between the treatment group and placebo. ${ }^{35}$

Despite the efficacy of progestational agents in the treatment of hot flashes, it can be associated with similar side effects as estrogen, and therefore it is contraindicated in women with thromboembolic disorders, impaired liver function, and undiagnosed uterine bleeding. ${ }^{24}$ The role of progestational agents in women with a history of breast cancer is still unclear. This is partially because it has been proposed that progestational agents may stimulate tumor growth. ${ }^{36}$ An epidemiological study failed to find any increase in breast cancer risk in women who used progesterone alone. ${ }^{37}$ Overall, the data on the association between progesterone and increased breast cancer risk is still controversial and to date no reliable conclusion can be made. ${ }^{24}$

\section{Tibolone}

Tibolone is a synthetic steroid that has both a weak estrogenic, progestagenic, and androgenic action. ${ }^{38}$ It is proposed that tibolone has tissue specific activity which is the result of metabolism, enzyme regulation, and receptor activation that vary in different tissues. ${ }^{39,40}$ Tibolone has been used for almost 20 years in Europe for the treatment of vasomotor symptoms, but is not available in the United States. ${ }^{19}$ A double-blind, randomized controlled trial of 437 postmenopausal women found that treatment with tibolone significantly reduced the mean scores for hot flashes and was comparable to estrogen therapy. ${ }^{41}$ The most common adverse effects were weight gain and bloating. ${ }^{38}$ However, the Million Women Study suggested that tibolone increased the risk of breast cancer. ${ }^{42}$ In addition, the Liberate trial showed that women with a history of breast cancer had increased recurrence of cancer if they were taking tibolone. ${ }^{43}$ On the other hand, a trial investigating the use of tibolone in postmenopausal women with low bone density found that the women using tibolone had a decrease in breast cancer events. ${ }^{44}$ One explanation for these various findings may be that tibolone affects healthy breast tissue differently than it does cancer cells. ${ }^{43}$ Additional research is needed to investigate the effect of tibolone on the risk of breast cancer in healthy postmenopausal women. ${ }^{45}$ At this time, tibolone should not be used in breast cancer patients, and should be used with caution in the general postmenopausal population.

\section{Non-hormonal therapy}

Many patients and physicians feel that the risks associated with hormonal therapy outweigh the therapeutic benefit. Consequently, nonhormonal therapies for hot flashes have received a significant amount of attention over the past 20 years.

\section{Centrally acting compounds Bellergal}

Bellergal is a combination product of belladonna alkaloids and phenobarbital. It was used in the 1970s and 1980s as 
a treatment for hot flashes. A placebo-controlled trial of 66 healthy women tested Bellergal Retard against placebo. The group of patients taking Bellergal had a decrease in the number of hot flashes by $75 \%$, versus $68 \%$ in the placebo group. This small improvement was not significant. ${ }^{46}$ Another study which included 50 patients demonstrated that patients taking Bellergal reported a moderate improvement in hot flashes over placebo. ${ }^{47}$ Adverse effects associated with Bellergal included dry mouth, dizziness, rash, and sleepiness. Due to the moderate efficacy and the availability of safer therapies, Bellergal is not recommended for the treatment of hot flashes.

\section{Clonidine}

Clonidine is a centrally acting $\alpha$-adrenergic agonist that was first proposed as a treatment for hot flashes in the 1970s. ${ }^{48-50}$ One proposed mechanism of action in the treatment of hot flashes is that clonidine raises the sweating threshold by reducing norepinephrine release. ${ }^{51}$ A randomized, double-blind, controlled trial was performed using a $0.1 \mathrm{mg}$ transdermal clonidine patch versus placebo in 110 women with a history of breast cancer. Patients receiving clonidine had an additional $20 \%$ reduction in hot flashes, as compared to the placebo group. However, patients experienced significant adverse effects including mouth dryness, constipation, itchiness, and drowsiness. ${ }^{52}$ Another randomized controlled trial evaluated the efficacy of oral clonidine in 149 postmenopausal women with breast cancer receiving tamoxifen therapy. After 8 weeks of treatment, the mean decrease in hot flash frequency was $38 \%$, as compared to $24 \%$ in the placebo group. Again, patients reported significant side effects, including difficulty sleeping. ${ }^{53}$ A recent metaanalysis included 10 trials of clonidine for the treatment of hot flashes and found inconsistent results, with half of the trials showing that clonidine was effective in treating hot flashes. ${ }^{54}$ Despite some positive results in these trials, the use of clonidine for hot flash treatment is not recommended because of significant side effects.

\section{Methyldopa}

Methyldopa is an antihypertensive agent that has been investigated as a treatment for hot flashes. A double-blind, placebo-controlled study was undertaken involving postmenopausal women, and demonstrated that $250 \mathrm{mg}$ of methyldopa was more effective than placebo at decreasing hot flashes. There was a $30 \%$ to $37 \%$ reduction in frequency of hot flashes in the methyldopa group, as compared to a $10 \%$ to $20 \%$ reduction in the placebo group. Adverse reactions including dizziness, nausea, and fatigue, occurred in 50\% of the patients. ${ }^{55}$ Therefore, due to its significant adverse affects, methyldopa is not recommended as a therapy for hot flashes.

\section{Veralipride}

Veralipride is a benzamide derivative with antidopaminergic effects, which has been studied as a treatment of hot flashes. A double-blind, randomized controlled study in 43 women compared treatment with veralipride to conjugated estrogens for the treatment of hot flashes. No significant difference in effectiveness or tolerance was found between the two treatments. ${ }^{56}$ Another trial tested veralipride versus placebo in healthy postmenopausal women. In this study, veralipride was associated with a significant reduction in hot flashes. ${ }^{57}$ Adverse effects of veralipride included breast tenderness, galactorrhea, gastrointestinal complaints, and dyspnea. ${ }^{58,59}$ Veralipride has also been associated with extraparamidal disorders, including acute dyskinesia and Parkinsonism. ${ }^{60}$ Due to its toxicities, veralipride is not approved for use in the United States and is currently not recommended for the treatment of hot flashes.

\section{Newer antidepressants}

In the 1990s it was recognized that women taking selective serotonin reuptake inhibitors (SSRI) had a decrease in hot flashes. ${ }^{9}$ As a result of these observations, it was hypothesized that such antidepressants may have a therapeutic effect on hot flashes. Since this time multiple randomized, placebo-controlled clinical trials have been undertaken to test this hypothesis, using several different agents. Overall, the results have been promising.

\section{Venlafaxine}

Venlafaxine selectively inhibits reuptake of serotonin, norepinephrine, and dopamine. Venlafaxine was first studied as a treatment for hot flashes in 1998 in a pilot trial which included 28 patients. This pilot trial involved both women with a history of breast cancer and men with prostate cancer who received androgen-deprivation therapy. The majority of patients reported a greater than $50 \%$ reduction in median hot flash scores after four weeks of treatment with venlafaxine, $12.5 \mathrm{mg}$ twice daily. In addition, treatment with venlafaxine also seemed to alleviate other symptoms, including fatigue, sweating, and trouble sleeping. At the completion of the study, $64 \%$ of patients chose to continue treatment with venlafaxine. ${ }^{61}$

The same group conducted a placebo-controlled, randomized clinical trial in order to further evaluate the 
efficacy of venlafaxine for hot flashes. This study included 191 women who were assigned to a placebo or to target venlafaxine doses of $37.5 \mathrm{mg}$ daily, $75 \mathrm{mg}$ daily, or $150 \mathrm{mg}$ daily. All venlafaxine treatment started at $37.5 \mathrm{mg}$ daily and gradually increased to the desired goal dose. After 4 weeks of treatment, hot flash scores reduced from baseline by $27 \%, 37 \%$, $61 \%$, and $61 \%$, respectively, in the four groups. Although the $75 \mathrm{mg} / \mathrm{d}$ dose had a greater effect than the $37.5 \mathrm{mg} / \mathrm{d}$ dose, $150 \mathrm{mg} / \mathrm{d}$ was not superior to $75 \mathrm{mg} /$ day. In fact the $150 \mathrm{mg}$ daily group had more side effects, including mouth dryness, decreased appetite, nausea, and constipation. ${ }^{62}$

Another randomized controlled trial of venlafaxine was performed in 80 postmenopausal women. Patients were randomized to receive extended-release venlafaxine at $37.5 \mathrm{mg}$ daily for 1 week, followed by $75 \mathrm{mg}$ daily for 11 weeks or placebo. In this trial, subjective assessments of hot flash symptoms on daily living were significantly improved in the treatment group. ${ }^{63}$ However, this trial did not collect any baseline hot flash data, which makes it difficult to interpret.

A more recent randomized controlled trial was undertaken comparing venlafaxine to DMPA in the management of hot flashes. This trial involved 109 women who were randomly assigned to receive DMPA $400 \mathrm{mg}$ intramuscularly as a single dose or venlafaxine $37.5 \mathrm{mg}$ daily for a week, then $75 \mathrm{mg}$ daily. After 6 weeks of treatment, there was a $55 \%$ reduction in hot flash score in the venlafaxine group, versus a $79 \%$ reduction in the DMPA group. In addition, less short-term toxicity was reported in the DMPA group. ${ }^{64}$ However, the safety of progesterone for treatment of hot flashes, especially in breast cancer patients remains controversial and this should be discussed with a patient prior to starting therapy.

\section{Desvenlafaxine}

Desvenlafaxine is a new serotonin norepinephrine reuptake inhibitor (SNRI) and is the succinate salt form of the major active metabolite of venlafaxine. ${ }^{65}$ Since venlafaxine was found to be successful in relieving hot flashes, it was hypothesized that desvenlafaxine may have a similar effect. A randomized, double-blind, placebo-controlled trial, including 707 healthy postmenopausal women, was undertaken to test this hypothesis. Women were randomized to receive desvenlafaxine $50 \mathrm{mg}, 100 \mathrm{mg}, 150 \mathrm{mg}, 200 \mathrm{mg}$, or placebo daily. There was no significant difference in hot flashes between the $50 \mathrm{mg}$ group (55\%) and placebo (51\%). However, there were significant reductions in the $100 \mathrm{mg}, 150 \mathrm{mg}$, and $250 \mathrm{mg}$ daily groups, with reductions of $64 \%, 60 \%$, and $60 \%$, respectively. The most common adverse drug reaction was nausea, which was dose-dependent. ${ }^{66}$ Another randomized, double-blind, placebo-controlled trial of desvenlafaxine for the treatment of hot flashes included 567 postmenopausal women who were assigned to receive desvenlafaxine $100 \mathrm{mg}$ or $150 \mathrm{mg}$ daily or placebo. After 12 weeks, reductions in the number of hot flashes in the $100 \mathrm{mg}, 150 \mathrm{mg}$, and placebo group were $60 \%, 66 \%$, and $47 \%$, respectively. ${ }^{67}$

\section{Paroxetine}

Paroxetine, an SSRI, was first explored as a treatment for hot flashes in a pilot trial conducted in 2000. The trial included 30 women with a history of breast cancer who received $10 \mathrm{mg}$ of paroxetine daily for one week followed by four weeks of $20 \mathrm{mg}$ daily. There was a significant reduction from baseline in hot flash frequency and score; $67 \%$ and $75 \%$, respectively. In addition, there were improvements in depression, sleep, anxiety and quality of life scores ${ }^{68}$ Based on these promising findings, a randomized controlled trial of paroxetine for the treatment of hot flashes was undertaken. This trial included 156 menopausal women who were randomized to receive paroxetine at $12.5 \mathrm{mg}$ daily, $25 \mathrm{mg}$ daily, or placebo. After 6 weeks of treatment there was a $62 \%$ reduction in hot flash score in the $12.5 \mathrm{mg}$ daily group, $65 \%$ reduction in the $25 \mathrm{mg}$ daily group, and a $38 \%$ reduction in placebo group. The most frequently reported side effects with paroxetine were headache, nausea, and insomnia. ${ }^{69}$ Another randomized, double-blind, cross-over, placebo-controlled trial involved 151 women who were assigned to receive 4 weeks of $10 \mathrm{mg}$ or $20 \mathrm{mg}$ of paroxetine followed by placebo, or placebo for 4 weeks followed by paroxetine $10 \mathrm{mg}$ or $20 \mathrm{mg}$. Paroxetine $10 \mathrm{mg}$ was found to reduce hot flash frequency by $40.6 \%$ compared to $13.7 \%$ with placebo. Paroxetine $20 \mathrm{mg}$ daily reduced the frequency by $51.7 \%$ compared to $26.6 \%$ with placebo. Overall, both doses of paroxetine had similar efficacy but the $10 \mathrm{mg}$ daily was better tolerated. ${ }^{70}$

\section{Fluoxetine}

Based on the positive results of previous trials of newer antidepressants and anecdotal information regarding the efficacy of fluoxetine in the treatment of hot flashes, a double-blind, randomized, cross-over study was performed. This trial included 81 women who were assigned to either fluoxetine $20 \mathrm{mg}$ daily or placebo, after 4 weeks the groups switched. After the first treatment period, there was a 50\% decrease in hot flash scores in the fluoxetine group versus a $36 \%$ reduction in placebo group. The cross-over analysis also found the fluoxetine group to have a greater reduction in hot 
flash score. There were no statistically significant toxicities experienced in treatment groups. ${ }^{71}$

Another randomized, placebo-controlled, study compared the efficacy of citalopram to fluoxetine in the treatment of hot flashes. This trial included 150 women who were randomized into three groups: placebo, fluoxetine, or citalopram. Fluoxetine and citalopram were started at $10 \mathrm{mg}$ and then increased to $20 \mathrm{mg}$ at one month, and $30 \mathrm{mg}$ at 6 months. The authors reported no statistically significant differences in the numbers of hot flashes between all groups. ${ }^{72}$ However, instead of collecting baseline hot flash data prior to initiation of the study treatments, the investigators used the first day of treatment as a baseline. ${ }^{73}$ This is problematic, because antidepressants can have a significant immediate effect on decreasing hot flashes. In fact, a 31\% reduction in hot flashes was seen in the first day of treatment with venlafaxine. ${ }^{73}$ Thus, the reported results of this trial are suspect.

\section{Citalopram}

Citalopram was first tested as a treatment for hot flashes in a pilot trial in 2003, which involved 26 women with a history of breast cancer. After 4 weeks of treatment at $10 \mathrm{mg}$ daily for the first week and $20 \mathrm{mg}$ daily for the following weeks, patients had a decrease in hot flash frequency by $58 \% .^{74}$ Another pilot trial evaluated the efficacy of citalopram for hot flash treatment in 22 patients who had inadequate relief while taking venlafaxine. After 4 weeks of treatment, hot flash scores were reduced by $53 \%$. Citalopram was well tolerated and at the end of the trial $86 \%$ of the original participants chose to continue treatment. ${ }^{75}$

These promising data led to further research, including randomized, placebo-controlled trials. One study involved 100 postmenopausal women who were randomized into four groups: citalopram, placebo, citalopram and hormone therapy, or placebo and hormone therapy. Mean hot flash scores improved in all groups with reductions of $37 \%, 13 \%$, $50 \%$, and $14 \%$, respectively. Thus, this study supported the previous findings that citalopram was successful in relieving hot flashes and found that its beneficial effect was increased with adjuvant hormonal therapy. Of note, women with a history of breast cancer, venous thromboembolism, or women who did not want to take hormone therapy were excluded from the hormone therapy treatment groups. ${ }^{76}$ A more recent randomized controlled trial was performed in 254 women who were allotted to receive either placebo or citalopram at $10 \mathrm{mg}$ daily, $20 \mathrm{mg}$ daily, or $30 \mathrm{mg}$ daily. Hot flash frequency decreased by $20 \%, 46 \%, 43 \%, 50 \%$, respectively. ${ }^{77}$

\section{CYP2D6}

Although newer antidepressants have shown to be a promising therapy for hot flashes, some of them may be contraindicated in breast cancer patients. Tamoxifen is a selective estrogen receptor modulator that is widely used for both the treatment and prevention of breast cancer. Tamoxifen is metabolized into its active metabolite, endoxifen, by a cytochrome $\mathrm{p} 450$ enzyme CYP2D6. ${ }^{78}$ Some newer antidepressants, especially paroxetine and fluoxetine, can inhibit this enzyme resulting in lower levels of endoxifen. Venlafaxine has less of an inhibitory effect on plasma levels of endoxifen. ${ }^{79}$ The effect of citalopram on plasma levels of endoxifen is less clear. However, the isoenzymes involved in the metabolism of citalopram are mainly CYP3A4 and CYP2D6 and thus it is not expected that citalopram would have very much of an effect on tamoxifen metabolism. ${ }^{75}$ Given currently available information, venlafaxine should, ideally, be selected if an antidepressant is chosen to treat a patient receiving tamoxifen.

\section{Gabapentin}

Gabapentin is structurally related to the neurotransmitter $\gamma$-aminobutyric acid and is currently used as an anticonvulsant and for neuropathic pain. Gabapentin was first recognized as a possible treatment for hot flashes in 2000 when Guttuso described 6 cases in which gabapentin treatment reduced the frequency of hot flashes. ${ }^{80}$ Based on these data, a pilot trial was reported in 2002, which involved 20 women. Patients were treated with gabapentin for 4 weeks with increasing doses from $300 \mathrm{mg}$ to $900 \mathrm{mg}$ daily. Patients taking gabapentin experienced a decrease in hot flash frequency of $66 \%{ }^{81}$

Since this time, multiple randomized controlled trials have evaluated the efficacy of gabapentin for the treatment of hot flashes. The first randomized, double-blind, placebo-controlled trial, involved 59 postmenopausal women who were treated with either $900 \mathrm{mg}$ daily of gabapentin or placebo. After 12 weeks of treatment, women receiving gabapentin experienced a $45 \%$ reduction in hot flash frequency, versus a $29 \%$ reduction seen in the placebo group. After the 12 week treatment period, there was an open-label treatment phase, during which patients increased the dose of gabapentin to $2700 \mathrm{mg}$ per day. This higher dose was associated with a $54 \%$ reduction in hot flash frequency and was not associated with increased adverse events. ${ }^{82}$ Another large randomized, double-blind, placebo-controlled trial involved 420 women with breast cancer and assigned them to receive placebo, gabapentin $300 \mathrm{mg}$ daily or $900 \mathrm{mg}$ daily. 
After 4 weeks, the reduction in hot flash severity scores was $21 \%, 33 \%, 49 \%$, respectively. Overall, gabapentin at $900 \mathrm{mg}$ daily was associated with a greater hot flash reduction than $300 \mathrm{mg}$ daily. ${ }^{83}$

The efficacy of gabapentin was then compared to estrogen and placebo in a third randomized controlled trial. This study involved 60 postmenopausal women who received either $625 \mu \mathrm{g} /$ day of conjugated estrogens, placebo, or gabapentin titrated to $2400 \mathrm{mg} /$ day. After 12 weeks, the hot flash composite score reduced by $72 \%$ in the estrogen group, $71 \%$ in the gabapentin group, and $54 \%$ in the placebo group. ${ }^{84}$ While this study supports a higher dose of gabapentin, the treatment groups only involved 20 women and the overall improvement was only $20 \%$ more than placebo. ${ }^{73}$ Therefore, the recommended dose for treatment of hot flashes is currently $900 \mathrm{mg} /$ day.

\section{Pregabalin}

Pregabalin is a newer generation compound with a mechanism of action similar to gabapentin. Therefore, it was hypothesized that it would also be effective against hot flashes. This hypothesis was first tested in a pilot study involving 6 patients and demonstrated a median reduction in hot flashes of $65 \%$ in patients taking pregabalin. ${ }^{85}$ To further investigate these positive findings, a randomized, double-blind, placebo-controlled trial was performed. 163 women either received pregabalin at a target dose of $75 \mathrm{mg}$ twice a day, $150 \mathrm{mg}$ twice a day, or placebo. After 6 weeks, hot flash scores decreased by $65 \%, 71 \%$, and $50 \%$, respectively. Toxicities included weight gain, sleepiness, dizziness, and cognitive troubles that were more significant with the higher dose. Nonetheless the dropout rates for toxicity were similar in all three groups, which implies that these symptoms were mild. ${ }^{86}$

\section{Complementary and alternative therapies}

\section{Phytoestrogens}

It has been reported that only $10 \%-20 \%$ of women in Asia experience hot flashes. This is significantly less than the $80 \%-90 \%$ prevalence in the United States. ${ }^{87,88}$ One theory for this difference is the predominance of soybeans and soy-based dishes in the Asian diet. Soy is a potent source of phytoestrogens, which are naturally occurring compounds with both estrogenic and anti-estrogenic properties. ${ }^{89}$ Phytoestrogens can be classified into two main classes: isoflavones and lignans. Recently, there has been interest in phytoestrogens as treatment for hot flashes.
Soy is a common source of isoflavones and has been studied as a treatment for hot flashes. In a randomized, double-blind, placebo-controlled trial, 91 perimenopausal women were given isoflavone-rich soy protein, isoflavone-poor soy protein, or whey protein. After 12 weeks there were no significant differences in hot flash frequency or severity between the 3 groups..$^{90}$ A recent meta-analysis reviewed 11 trials of soy isoflavone extracts for treatment of hot flashes and overall the data was not positive. ${ }^{54}$ Soy phytoestrogens were also explored for the treatment of hot flashes in breast cancer patients. One double-blind clinical trial involved 177 breast cancer survivors who received either soy tablets or placebo. After 4 weeks there was no difference in hot flash frequency between groups. This trial had a double-blind cross-over component. The cross-over study results were also negative. Interestingly, at the end of the trial more women chose to continue placebo than the soy product. ${ }^{91}$ Further clinical trials of soy phytoestrogens in breast cancer patients also showed similar negative results. ${ }^{92}$

Isoflavones can also be derived from red clover. A large clinical trial tested two dietary supplements derived from red clover, promensil and rimostil. 252 menopausal women were randomized to receive promensil, rimostil, or placebo. After 12 weeks there was no clinically important reduction in hot flash frequency in either treatment group..$^{93} \mathrm{~A}$ recent meta-analysis reviewed 6 trials of red clover for the treatment of hot flashes with similar negative results. ${ }^{54}$

Lignan is another form of phytoestrogen, which is found in whole grains, legumes, vegetables, and in especially high concentrations in flaxseed. ${ }^{89}$ Lignan is structurally similar to estradiol and tamoxifen and has possible tumor inhibitory effects on estrogen positive breast cancer. ${ }^{94}$ An increasing amount of research is currently being undertaken on flaxseed as a treatment for hot flashes. A pilot trial involved 30 women who received $40 \mathrm{~g}$ of crushed flaxseed daily. After 6 weeks of therapy there was a $50 \%$ reduction in hot flash frequency. ${ }^{95}$ A double-blind, randomized controlled trial included 87 women who ingested either muffins with $25 \mathrm{~g}$ of flaxseed, $25 \mathrm{~g}$ grams of soy, or wheat. After 16 weeks, neither flaxseed or soy flour affected hot flash frequency but there was a significant reduction in severity of hot flashes for those consuming the flaxseed muffins. ${ }^{96}$ Another double-blind, placebo-controlled, randomized clinical trial of flaxseed has completed its accrual goals and, hopefully, should be reported by 2011. A recent Cochrane metaanalysis summarizes the findings of 30 clinical trials, which investigated the effect of various forms of phytoestrogens on hot flashes. According to this meta-analysis there is currently 
no evidence that phytoestrogen supplementation reduces either the frequency or severity of hot flashes. ${ }^{97}$ However, a meta-analysis of isoflavone therapy did report a slight to modest reduction in the number of hot flashes experienced by menopausal women. ${ }^{98}$ Therefore, although at this time phytoestrogens are not recommended for the treatment of hot flashes, it is quite feasible that with further research some phytoestrogen products will be demonstrated to be effective in the alleviation of hot flashes.

\section{Black cohosh}

Black cohosh, also known as Cimicifuga racemosa, is a plant native to the eastern United States and Canada. American Indians originally used it as a remedy for menstrual and menopausal conditions. ${ }^{99}$ A meta-analysis reviewed 4 randomized controlled trials of black cohosh and this report stated that 3 of the 4 trials found black cohosh to be beneficial for the treatment of hot flashes. ${ }^{92}$ However, most of these trials were from the 1980s. More recent clinical trials have not found any beneficial effect from black cohosh. In 2006, a double-blind, randomized cross-over clinical trial was undertaken where patients received black cohosh for 4 weeks and then placebo or placebo and then black cohosh treatment. The trial failed to show any evidence that black cohosh was more effective at relieving hot flashes than placebo. ${ }^{100} \mathrm{~A}$ recent randomized, double-blind clinical trial from 2009 compared black cohosh, red clover and placebo for the relief of hot flashes. 89 women were randomized to receive black cohosh $128 \mathrm{mg} /$ day, red clover $120 \mathrm{mg} /$ day, or hormone therapy ( $625 \mu \mathrm{g}$ estrogen and $2.5 \mathrm{mg}$ progestin). At the end of 12 months the reduction in vasomotor symptoms was $34 \%$ in the black cohosh group, $57 \%$ in the red clover group, $63 \%$ in the placebo group, and $94 \%$ in the hormone therapy group. Thus, neither red clover nor black cohosh significantly reduced hot flashes. ${ }^{101}$ In addition, there is some concern regarding possible adverse effects of black cohosh on the liver and its overall long-term safety. ${ }^{19,92}$ Therefore, black cohosh is not recommended as a treatment for hot flashes

\section{Vitamin E}

Vitamin E was first recognized as a possible treatment for hot flashes in the 1940s. ${ }^{102,103}$ The first randomized, cross-over, clinical trial took place in 1998 when 120 women received 4 weeks of vitamin E (800 IU daily) then 4 weeks of placebo or vice versa. On crossover analysis, vitamin E was associated with a reduction of hot flashes of about 1 hot flash per day. However, at the end of the study patients did not prefer vitamin E over the placebo. ${ }^{104}$ In recent years there has been concern about the carcinogenicity of vitamin $\mathrm{E}$, however there is reported evidence that vitamin $\mathrm{E}$ does not increase cancer risk. ${ }^{105}$ Therefore, at this time vitamin E cannot be strongly recommended as an effective treatment for hot flashes.

\section{DHEA}

Dehydroepiandrosterone (DHEA) is proandrogen produced by the adrenal glands and liver. It is proposed that DHEA levels decrease as women age and supplementing DHEA may have some effect in treating menopausal symptoms. ${ }^{106,107}$ A small trial in 2000 studied 6 months of DHEA supplementation in postmenopausal women and reported a significant decrease in vasomotor symptoms. ${ }^{108} \mathrm{~A}$ more recent pilot study was performed in 22 women and found a decrease in mean hot flash scores of $50 \%$ and an improvement in quality of life related to hot flashes after 4 weeks of DHEA therapy. ${ }^{106}$ These positive findings still need to be evaluated in a large randomized placebo-controlled trial.

\section{Other herbal remedies}

Evening primrose oil (Oenothera biennis) is rich in linoleic acid and is extracted from seeds of the evening primrose plant. ${ }^{109}$ A randomized, double-blind, placebo-controlled study was undertaken to evaluate the efficacy of evening primrose oil in treating hot flushes and found that evening primrose oil to have no benefit for hot flash relief. ${ }^{110}$

Dong quai (Angelica sinensis) is a Chinese herb which is traditionally used to treat menopausal symptoms. A randomized controlled trial in 71 women demonstrated no difference in hot flashes between dong quai treatment and placebo groups. ${ }^{111}$ In addition, dong quai has been found to have estrogen like activity. ${ }^{112,113}$ Therefore, not only does dong quai lack any established efficacy for treating hot flashes, its safety in breast cancer patients remains unclear.

Ginseng (Panax ginseng) is one of the most popular herbal supplements sold in the United States. It is often used as a restorative agent to treat fatigue or exhaustion. ${ }^{109}$ A randomized double-blind trial investigated the effects of ginseng extract on the quality of life and physiological parameters in women experiencing hot flashes. There was no significant difference in vasomotor symptoms between the treatment group and a placebo group. ${ }^{114}$

Wild Yam (Dioscorea villosa) is a natural progesterone cream, which contains phytosteroids and has been promoted for the treatment of hot flashes. ${ }^{115}$ However, a double-blind, placebo-controlled, cross-over study found no significant difference in menopausal symptoms between the treatment and placebo group. ${ }^{116}$ 
Currently there is no sound evidence demonstrating that evening primrose oil, dong quai, ginseng, or wild yam are effective in treating hot flashes and therefore should not be used as a therapy for vasomotor symptoms.

\section{Mind-body and behavior therapies}

Behavioral modifications

Despite the large variety of pharmacological options for the treatment of hot flashes, the North American Menopause Society recommends lifestyle changes as the first line therapy for patients suffering from mild vasomotor symptoms. ${ }^{117}$ One key lifestyle modification involves keeping the core body temperature cool using techniques such as loose clothing, sipping cold drinks, avoiding spicy food, and keeping a lower room temperature. ${ }^{117,118}$

\section{Exercise}

An increasing amount of research is being undertaken on the effect of exercise on hot flashes. However, there is currently no evidence from randomized controlled trials that show that exercise is an effective treatment for hot flashes. ${ }^{119,120}$

\section{Yoga}

Yoga is a combination of exercise and meditation, which involves gentle stretching and breath control. Recently yoga has been studied as a treatment for menopausal symptoms. One large clinical trial involved 108 women who received either 8 weeks of yoga or regular physical exercises. The symptom assessment was made using the Greene Climacteric Scale and it was reported that there was a decrease in vasomotor symptoms in the group involved in the yoga program. ${ }^{121}$

A recent randomized pilot trial studied the use of yoga for hot flash treatment in breast cancer survivors. This study involved 37 breast cancer survivors who received either 8 weeks of yoga or were on a wait-list control. After the treatment, women who were involved in the yoga program showed improvements in hot flash frequency, severity, and total scores. ${ }^{122}$ However, the reduction in hot flash score was only $31 \%$, which could be attributed to placebo response. A recent review of the literature on this topic concluded that current evidence does not support the use of yoga for menopausal symptoms. ${ }^{123}$ Further research is needed to better investigate this area.

\section{Relaxation training}

Relaxation techniques are methods of reducing stress and anxiety. Many different forms of relaxation have been investigated for the treatment of menopausal symptoms. One form of relaxation training is paced breathing, which involves slow, rhythmic, diaphragmatic breathing. Small randomized trials have investigated paced breathing for hot flashes and claimed positive results. ${ }^{124,125}$ These encouraging results led to a randomized phase II study to evaluate the efficacy of paced breathing for hot flashes; the results from this trial, which has completed its accrual goal, are pending.

The efficacy of relaxation as a treatment for hot flashes has also been studied in breast cancer patients. A recent randomized controlled trial investigating relaxation involved 150 women with a history of breast cancer who received either a single relaxation training session with instruction to use practice tapes daily for one month versus no intervention. After one month, the incidence and severity of hot flashes significantly declined in the treatment group. However, there was no difference between groups at 3 months. ${ }^{126}$

Mindfulness-based stress reduction (MBSR) is another form of trained relaxation. It is a program that teaches mindfulness meditation and yoga as a way to cope with stress. ${ }^{127}$ A pilot study investigated the effect of an MBSR program on hot flashes. This study included 15 women who attended the 8-week MBSR program. At the end of the 11-week assessment period, the hot flash severity decreased by $40 \% .{ }^{128}$ However, this may result from a placebo effect alone.

A recent review of the literature on the efficacy of relaxation techniques on hot flash control concluded that most trials had positive results. However, the trials were designed with small sample sizes and included a variety of interventions and outcome measures. Therefore, more large well-designed randomized controlled trials are needed to further evaluate the efficacy of these various forms of relaxation on hot flash control. ${ }^{129}$

\section{Hypnosis}

Hypnosis is a mind-body therapy that uses mental imagery to induce a state of deep relaxation and heightened focus. Hypnosis has been found to be useful in the management of multiple medical conditions including pain, anxiety, and insomnia. ${ }^{130-133}$ It also has been reported to reduce anxiety and distress in breast cancer patients. ${ }^{134-136}$ Hot flashes are often associated with anxiety and stress. Therefore, it has been proposed that hypnosis may act to reduce hot flashes. This theory was evaluated by a pilot trial of hypnosis in breast cancer patients suffering from hot flashes. The trial reported positive results, with a $59 \%$ decrease in total daily hot flashes from baseline. ${ }^{137} \mathrm{~A}$ larger trial of hypnosis for the treatment of hot flashes was performed in 51 breast cancer survivors and found similar results with hot flashes decreasing by $68 \%$ in the hypnosis group. ${ }^{138}$ These preliminary data are encouraging and larger randomized clinical trials of hypnosis for hot flashes are currently underway. 


\section{Acupuncture}

Acupuncture involves the use of thin needles inserted into specific points of the body. It has been used in Asia for thousands of years and has recently gained popularity in the west as a treatment for multiple conditions. Over the past decade many trials have explored the effect of acupuncture on hot flash symptoms. A recent review of the literature included trials of acupuncture for the treatment of hot flashes that were performed prior to July 2008. This review included six trials that compared acupuncture treatment to sham or placebo acupuncture, five of those trials found no significant difference between groups. ${ }^{139}$ Another recent review explored the literature regarding the effect of acupuncture on hot flashes in breast cancer patients. This review found three randomized controlled trials, which compared the effects of acupuncture to sham procedure. Two of these trials failed to show any positive results from the acupuncture. ${ }^{140}$ Therefore, to date, there is no evidence that acupuncture is an effective treatment for hot flashes.

\section{Stellate sanglion block}

Stellate ganglion block (SGB) is commonly used to treat a variety of pain syndromes and vascular insufficiency. ${ }^{141}$ The positive effect of SGB on hot flashes was first reported in a case report by Lipov and colleagues. The series involved 6 women, all of whom experienced a significant reduction in hot flashes after the SGB. ${ }^{142}$ In response to these encouraging results the same researchers performed a pilot study involving 13 women with a history of breast cancer. Again, it was reported that a SBG significantly reduced the frequency and severity of hot flashes. In addition, there were no significant adverse events related to the procedure. ${ }^{143} \mathrm{~A}$ more recent pilot trial was undertaken to evaluate the efficacy of SGB for hot flashes and involved 9 women with a history of breast cancer. The results of this pilot trial supported those reported by Lipov and colleagues. ${ }^{144}$

The mechanism by which SGB might reduce hot flashes is unclear. However, Lipov and colleagues proposed that the stellate ganglion has links with the areas of the central nervous system that control body temperature. A SGB may interrupt these connections and allow the body temperature regulating mechanisms to reset. ${ }^{145}$ Large randomized controlled trials are needed to further clarify the use of SGB for hot flashes, and are currently underway.

\section{Conclusion}

Hot flashes are one of the most common and distressing symptoms associated with menopause. Hot flashes are especially problematic because the most well recognized effective treatment, estrogen, is often contraindicated. This dilemma has lead to an extensive amount of research exploring different therapeutic options for the treatment of hot flashes. Currently, multiple safe and efficacious non-hormonal modalities exist. As the mechanism of hot flashes is further elucidated and research in this area grows, newer therapies for hot flashes will most likely become established.

\section{Disclosure}

The authors report no conflicts of interest in this work.

\section{References}

1. Grady D. Clinical practice. Management of menopausal symptoms. N Engl J Med. 2006;355(22):2338-2347.

2. Couzi R, Helzlsouer K, Fetting J. Prevelance of menopausal symptoms amoung women with a history of breast cancer and attitudes toward estrogen replacement therapy. Journal of Clinical Oncology. 1995; 13(11):2737-2744

3. Kronenberg F. Hot flashes: epidemiology and physiology. Ann NYAcad Sci. 1990;592:52-86.

4. McKinlay SM, Jefferys M. The menopausal syndrome. Br J Prev Soc Med. 1974;28(2):108-115.

5. Daly E, Gray A, Barlow D, McPherson K, Roche M, Vessey M. Measuring the impact of menopausal symptoms on quality of life. BMJ. 1993;307(6908):836-840.

6. Loprinzi C, Barton D, Rhodes D. Management of hot flashes in breast-cancer survivors. Lancet Oncol. 2001;2:199-204.

7. Love RR, Cameron L, Connell BL, Leventhal H. Symptoms associated with tamoxifen treatment in postmenopausal women. Arch Intern Med. 1991;151(9):1842-1847.

8. Carpenter JS, Andrykowski MA. Menopausal symptoms in breast cancer survivors. Oncol Nurs Forum. 1999;26(8):1311-1317.

9. Shanafelt TD, Barton DL, Adjei AA, Loprinzi CL. Pathophysiology and treatment of hot flashes. Mayo Clin Proc. 2002;77(11):1207-1218.

10. Casper RF, Yen SS. Neuroendocrinology of menopausal flushes: an hypothesis of flush mechanism. Clin Endocrinol (Oxf). 1985; 22(3):293-312.

11. Sturdee DW. The menopausal hot flush - anything new? Maturitas. 2008;60(1):42-49.

12. Freedman RR. Physiology of hot flashes. Am J Hum Biol. 2001; 13(4):453-464.

13. Freedman RR, Krell W. Reduced thermoregulatory null zone in postmenopausal women with hot flashes. Am J Obstet Gynecol. 1999; 181(1):66-70.

14. Berendsen $\mathrm{HH}$. The role of serotonin in hot flushes. Maturitas. 2000;36(3):155-164.

15. Maclennan AH, Broadbent JL, Lester S, Moore V. Oral oestrogen and combined oestrogen/progestogen therapy versus placebo for hot flushes. Cochrane Database Syst Rev. 2004(4):CD002978.

16. Notelovitz M, Lenihan JP, McDermott M, Kerber IJ, Nanavati N, Arce J. Initial 17 beta-estradiol dose for treating vasomotor symptoms. Obstet Gynecol. 2000;95(5):726-731.

17. Utian WH, Archer DF, Bachmann GA, et al. Estrogen and progestogen use in postmenopausal women: 2008 position statement of The North American Menopause Society. Menopause. 2008; 15(4 Pt 1):584-602.

18. Rossouw JE, Anderson GL, Prentice RL, et al. Risks and benefits of estrogen plus progestin in healthy postmenopausal women: principal results From the Women's Health Initiative randomized controlled trial. Jama. 2002;288(3):321-333.

19. NIH State-of-the-Science Panel on Management of Menopause-Related Symtpoms. National Institutes of Health State-of-the-Science Conference statement: management of menopause-related symptoms. Ann Intern Med. 2005;142(12 Pt 1):1003-1013.

20. Bachmann GA, Schaefers M, Uddin A, Utian WH. Lowest effective transdermal 17beta-estradiol dose for relief of hot flushes in postmenopausal women: a randomized controlled trial. Obstet Gynecol. 2007;110(4):771-779. 
21. Hedrick RE, Ackerman RT, Koltun WD, Halvorsen MB, Lambrecht LJ. Transdermal estradiol gel $0.1 \%$ for the treatment of vasomotor symptoms in postmenopausal women. Menopause. 2009;16(1):132-140.

22. Simon JA, Snabes MC. Menopausal hormone therapy for vasomotor symptoms: balancing the risks and benefits with ultra-low doses of estrogen. Expert Opin Investig Drugs. 2007;16(12):2005-2020.

23. Hoda D, Perez DG, Loprinzi CL. Hot flashes in breast cancer survivors. Breast J. 2003;9(5):431-438.

24. The North American Menopause Society. Role of progestogen in hormone therapy for postmenopausal women: position statement of The North American Menopause Society. Menopause. 2003;10(2):113-132.

25. Loprinzi CL, Michalak JC, Quella SK, et al. Megestrol acetate for the prevention of hot flashes. N Engl J Med. 1994;331(6):347-352.

26. Quella SK, Loprinzi CL, Sloan JA, et al. Long term use of megestrol acetate by cancer survivors for the treatment of hot flashes. Cancer. 1998;82(9):1784-1788.

27. Goodwin JW, Green SJ, Moinpour CM, et al. Phase III randomized placebo-controlled trial of two doses of megestrol acetate as treatment for menopausal symptoms in women with breast cancer: Southwest Oncology Group Study 9626. J Clin Oncol. 2008;26(10):1650-1656.

28. Bullock JL, Massey FM, Gambrell RD Jr. Use of medroxyprogesterone acetate to prevent menopausal symptoms. Obstet Gynecol. 1975; 46(2):165-168.

29. Lobo RA, McCormick W, Singer F, Roy S. Depo-medroxyprogesterone acetate compared with conjugated estrogens for the treatment of postmenopausal women. Obstet Gynecol. 1984;63(1):1-5.

30. Morrison JC, Martin DC, Blair RA, et al. The use of medroxyprogesterone acetate for relief of climacteric symptoms. Am J Obstet Gynecol. 1980 138(1):99-104.

31. Bertelli G, Venturini M, Del Mastro L, et al. Intramuscular depot medroxyprogesterone versus oral megestrol for the control of postmenopausal hot flashes in breast cancer patients: a randomized study. Ann Oncol. 2002;13(6):883-888.

32. Barton D, Loprinzi C, Quella S, Sloan J, Pruthi S, Novotny P. Depomedroxyprogesterone acetate for hot flashes. J Pain Symptom Manage. 2002;24(6):603-607.

33. Prior JC, Nielsen JD, Hitchcock CL, Williams LA, Vigna YM, Dean CB Medroxyprogesterone and conjugated oestrogen are equivalent for hot flushes: a 1-year randomized double-blind trial following premenopausal ovariectomy. Clin Sci (Lond). 2007;112(10):517-525.

34. Leonetti HB, Longo S, Anasti JN. Transdermal progesterone cream for vasomotor symptoms and postmenopausal bone loss. Obstet Gynecol. 1999;94(2):225-228

35. Benster B, Carey A, Wadsworth F, Vashisht A, Domoney C, Studd J. A double-blind placebo-controlled study to evaluate the effect of progestelle progesterone cream on postmenopausal women. Menopause Int. 2009;15(2):63-69.

36. Hofseth LJ, Raafat AM, Osuch JR, Pathak DR, Slomski CA, Haslam SZ. Hormone replacement therapy with estrogen or estrogen plus medroxyprogesterone acetate is associated with increased epithelial proliferation in the normal postmenopausal breast. J Clin Endocrinol Metab. 1999;84(12):4559-4565.

37. Schairer C, Lubin J, Troisi R, Sturgeon S, Brinton L, Hoover R. Menopausal estrogen and estrogen-progestin replacement therapy and breast cancer risk. JAMA. 2000;283(4):485-491.

38. Albertazzi P, Di Micco R, Zanardi E. Tibolone: a review. Maturitas. 1998;30(3):295-305.

39. Kloosterboer HJ. Tissue-selectivity: the mechanism of action of tibolone. Maturitas. 2004;48 Suppl 1:S30-S40.

40. Palacios S. Tibolone: what does tissue specific activity mean? Maturitas. 2001;37(3):159-165.

41. Hammar M, Christau S, Nathorst-Boos J, Rud T, Garre K. A double-blind, randomised trial comparing the effects of tibolone and continuous combined hormone replacement therapy in postmenopausal women with menopausal symptoms. Br J Obstet Gynaecol. 1998;105(8):904-911.
42. Beral V. Breast cancer and hormone-replacement therapy in the Million Women Study. Lancet. 2003;362(9382):419-427.

43. Kenemans P, Bundred NJ, Foidart JM, et al. Safety and efficacy of tibolone in breast-cancer patients with vasomotor symptoms: a double-blind, randomised, non-inferiority trial. Lancet Oncol. 2009; 10(2):135-146.

44. Cummings SR, Ettinger B, Delmas PD, et al. The effects of tibolone in older postmenopausal women. $N$ Engl J Med. 2008;359(7):697-708.

45. Goodwin PJ. Tibolone: the risk is too high. Lancet Oncol. 2009; 10(2):103-104.

46. Bergmans MG, Merkus JM, Corbey RS, Schellekens LA, Ubachs JM. Effect of Bellergal Retard on climacteric complaints: a double-blind, placebo-controlled study. Maturitas. 1987;9(3):227-234.

47. Lebherz TB, French L. Nonhormonal treatment of the menopausal syndrome. A double-blind evaluation of an autonomic system stabilizer. Obstet Gynecol. 1969;33(6):795-799.

48. Schindler AE, Muller D, Keller E, Goser R, Runkel F. Studies with clonidine (dixarit) in menopausal women. Arch Gynecol. 1979; 227(4):341-347.

49. Clayden JR, Bell JW, Pollard P. Menopausal flushing: double-blind trial of a non-hormonal medication. Br Med J. 1974;1(5905):409-412.

50. Laufer LR, ErlikY, Meldrum DR, Judd HL. Effect of clonidine on hot flashes in postmenopausal women. Obstet Gynecol. 1982; 60(5):583-586.

51. Freedman RR, Dinsay R. Clonidine raises the sweating threshold in symptomatic but not in asymptomatic postmenopausal women. Fertil Steril. 2000;74(1):20-23.

52. Goldberg RM, Loprinzi CL, O'Fallon JR, et al. Transdermal clonidine for ameliorating tamoxifen-induced hot flashes. J Clin Oncol. 1994; 12(1):155-158.

53. Pandya KJ, Raubertas RF, Flynn PJ, et al. Oral clonidine in postmenopausal patients with breast cancer experiencing tamoxifeninduced hot flashes: a University of Rochester Cancer Center Community Clinical Oncology Program study. Ann Intern Med. 2000;132(10):788-793.

54. Nelson HD, Vesco KK, Haney E, et al. Nonhormonal therapies for menopausal hot flashes: systematic review and meta-analysis. Jama. 2006;295(17):2057-2071.

55. Hammond MG HL, Talbert LM. A double-blind study to evaluate the effect of methydopa on menopausal vasomotor flushes. J Clin Endocrinol Metab. 1984;58:1158-1160.

56. Wesel S, Bourguignon RP, Bosuma WB. Veralipride versus conjugated oestrogens: a double-blind study in the management of menopausal hot flushes. Curr Med Res Opin. 1984;8(10):696-700.

57. Melis GB, Gambacciani M, Cagnacci A, Paoletti AM, Mais V, Fioretti P. Effects of the dopamine antagonist veralipride on hot flushes and luteinizing hormone secretion in postmenopausal women. Obstet Gynecol. 1988;72(5):688-692.

58. David A, Don R, Tajchner G, Weissglas L. Veralipride: alternative antidopaminergic treatment for menopausal symptoms. Am J Obstet Gynecol. 1988;158(5):1107-1115.

59. Vercellini P, Vendola N, Colombo A, Passadore C, Trespidi L, Crosignani PG. Veralipride for hot flushes during gonadotropinreleasing hormone agonist treatment. Gynecol Obstet Invest. 1992; 34(2):102-104.

60. De Leo V, Morgante G, Musacchio MC, Faldini E, Delia A, Petraglia F. The safety of veralipride. Expert Opin Drug Saf. 2006;5(5):695-701.

61. Loprinzi CL, Pisansky TM, Fonseca R, et al. Pilot evaluation of venlafaxine hydrochloride for the therapy of hot flashes in cancer survivors. J Clin Oncol. 1998;16(7):2377-2381.

62. Loprinzi CL, Kugler JW, Sloan JA, et al. Venlafaxine in management of hot flashes in survivors of breast cancer: a randomised controlled trial. Lancet. 2000;356(9247):2059-2063.

63. Evans ML, Pritts E, Vittinghoff E, McClish K, Morgan KS, Jaffe RB. Management of postmenopausal hot flushes with venlafaxine hydrochloride: a randomized, controlled trial. Obstet Gynecol. 2005;105(1):161-166

64. Loprinzi CL, Levitt R, Barton D, et al. Phase III comparison of depomedroxyprogesterone acetate to venlafaxine for managing hot flashes: North Central Cancer Treatment Group Trial N99C7. J Clin Oncol. 2006;24(9):1409-1414. 
65. Deecher DC, Alfinito PD, Leventhal L, et al. Alleviation of thermoregulatory dysfunction with the new serotonin and norepinephrine reuptake inhibitor desvenlafaxine succinate in ovariectomized rodent models. Endocrinology. 2007;148(3):1376-1383.

66. Speroff L, Gass M, Constantine G, Olivier S. Efficacy and tolerability of desvenlafaxine succinate treatment for menopausal vasomotor symptoms: a randomized controlled trial. Obstet Gynecol. 2008;111(1):77-87.

67. Archer DF, Dupont CM, Constantine GD, Pickar JH, Olivier S. Desvenlafaxine for the treatment of vasomotor symptoms associated with menopause: a double-blind, randomized, placebo-controlled trial of efficacy and safety. Am J Obstet Gynecol. 2009;200(3):238 e231-238 e210.

68. Stearns $\mathrm{V}$, Isaacs $\mathrm{C}$, Rowland $\mathrm{J}$, et al. A pilot trial assessing the efficacy of paroxetine hydrochloride (Paxil) in controlling hot flashes in breast cancer survivors. Ann Oncol. 2000;11(1):17-22.

69. Stearns V, Beebe KL, Iyengar M, Dube E. Paroxetine controlled release in the treatment of menopausal hot flashes: a randomized controlled trial. Jama. 2003;289(21):2827-2834.

70. Stearns V, Slack R, Greep N, et al. Paroxetine is an effective treatment for hot flashes: results from a prospective randomized clinical trial. J Clin Oncol. 2005;23(28):6919-6930.

71. Loprinzi CL, Sloan JA, Perez EA, et al. Phase III evaluation of fluoxetine for treatment of hot flashes. J Clin Oncol. 2002;20(6):1578-1583.

72. Suvanto-Luukkonen E, Koivunen R, Sundstrom H, et al. Citalopram and fluoxetine in the treatment of postmenopausal symptoms: a prospective, randomized, 9-month, placebo-controlled, double-blind study. Menopause. 2005;12(1):18-26.

73. Loprinzi CL, Sloan J, Stearns V, et al. Newer antidepressants and gabapentin for hot flashes: an individual patient pooled analysis. J Clin Oncol. 2009;27(17):2831-2837.

74. Barton DL, Loprinzi CL, Novotny P, et al. Pilot evaluation of citalopram for the relief of hot flashes. J Support Oncol. 2003;1(1):47-51.

75. Loprinzi CL, Flynn PJ, Carpenter LA, et al. Pilot evaluation of citalopram for the treatment of hot flashes in women with inadequate benefit from venlafaxine. J Palliat Med. 2005;8(5):924-930.

76. Kalay AE, Demir B,HaberalA, Kalay M,KandemirO. Efficacy of citalopram on climacteric symptoms. Menopause. 2007;14(2):223-229.

77. Barton DL, LaVasseur B, Sloan JA, et al. A phase III trial evaluating three doses of citalopram for hot flashes: NCCTG trial N05C9. J Clin Oncol. 2008;26(20):9538.

78. Jin Y, Desta Z, Stearns V, et al. CYP2D6 genotype, antidepressant use, and tamoxifen metabolism during adjuvant breast cancer treatment. J Natl Cancer Inst. 2005;97(1):30-39.

79. Otton SV, Ball SE, Cheung SW, Inaba T, Rudolph RL, Sellers EM. Venlafaxine oxidation in vitro is catalysed by CYP2D6. $\mathrm{Br} J$ Clin Pharmacol. 1996;41(2):149-156.

80. Guttuso TJ Jr. Gabapentin's effects on hot flashes and hypothermia. Neurology. 2000;54(11):2161-2163.

81. Loprinzi L, Barton DL, Sloan JA, et al. Pilot evaluation of gabapentin for treating hot flashes. Mayo Clin Proc. 2002;77(11):1159-1163.

82. Guttuso T, Jr., Kurlan R, McDermott MP, Kieburtz K. Gabapentin's effects on hot flashes in postmenopausal women: a randomized controlled trial. Obstet Gynecol. 2003;101(2):337-345.

83. Pandya KJ, Morrow GR, Roscoe JA, et al. Gabapentin for hot flashes in 420 women with breast cancer: a randomised double-blind placebo-controlled trial. Lancet. 2005;366(9488):818-824.

84. Reddy SY, Warner H, Guttuso T Jr, et al. Gabapentin, estrogen, and placebo for treating hot flushes: a randomized controlled trial. Obstet Gynecol. 2006;108(1):41-48.

85. Presant CA KC. Palliation of vasomotor instability (hot flashes) using pregabalin. Community Oncol. 2007;4:83-84.

86. Loprinzi CL, Qin R, Baclueva EP, et al. Phase III, randomized, double-blind, placebo-controlled evaluation of pregabalin for alleviating hot flashes, N07C1. J Clin Oncol. 2010;28(4):641-647.

87. Freeman EW, Sherif K. Prevalence of hot flushes and night sweats around the world: a systematic review. Climacteric. 2007; 10(3):197-214.
88. Oddens BJ. The climacteric cross-culturally: the International Health Foundation South-east Asia study. Maturitas. 1994;19(3): $155-156$.

89. Tham DM, Gardner CD, Haskell WL. Clinical review 97: Potential health benefits of dietary phytoestrogens: a review of the clinical, epidemiological, and mechanistic evidence. J Clin Endocrinol Metab. 1998;83(7):2223-2235.

90. St Germain A, Peterson CT, Robinson JG, Alekel DL. Isoflavone-rich or isoflavone-poor soy protein does not reduce menopausal symptoms during 24 weeks of treatment. Menopause. 2001;8(1):17-26.

91. Quella SK, Loprinzi CL, Barton DL, et al. Evaluation of soy phytoestrogens for the treatment of hot flashes in breast cancer survivors: A North Central Cancer Treatment Group Trial. J Clin Oncol. 2000;18(5):1068-1074.

92. Kronenberg F, Fugh-Berman A. Complementary and alternative medicine for menopausal symptoms: a review of randomized, controlled trials. Ann Intern Med. 2002;137(10):805-813.

93. Tice JA, Ettinger B, Ensrud K, Wallace R, Blackwell T, Cummings SR. Phytoestrogen supplements for the treatment of hot flashes: the Isoflavone Clover Extract (ICE) Study: a randomized controlled trial. JAMA. 2003;290(2):207-214.

94. Chen J, Hui E, Ip T, Thompson LU. Dietary flaxseed enhances the inhibitory effect of tamoxifen on the growth of estrogen-dependent human breast cancer (mcf-7) in nude mice. Clin Cancer Res. 2004; 10(22):7703-7711.

95. Pruthi S, Thompson SL, Novotny PJ, et al. Pilot evaluation of flaxseed for the management of hot flashes. J Soc Integr Oncol. 2007;5(3):106-112.

96. Lewis JE, Nickell LA, Thompson LU, Szalai JP, Kiss A, Hilditch JR. A randomized controlled trial of the effect of dietary soy and flaxseed muffins on quality of life and hot flashes during menopause. Menopause. 2006;13(4):631-642.

97. Lethaby AE, Brown J, Marjoribanks J, Kronenberg F, Roberts H, Eden J. Phytoestrogens for vasomotor menopausal symptoms. Cochrane Database Syst Rev. 2007(4):CD001395.

98. Howes LG, Howes JB, Knight DC. Isoflavone therapy for menopausal flushes: a systematic review and meta-analysis. Maturitas. 2006; 55(3): 203-211.

99. Wade C, Kronenberg F, Kelly A, Murphy PA. Hormone-modulating herbs: implications for women's health. J Am Med Womens Assoc. 1999;54(4):181-183.

100. Pockaj BA, Gallagher JG, Loprinzi CL, et al. Phase III double-blind, randomized, placebo-controlled crossover trial of black cohosh in the management of hot flashes: NCCTG Trial N01CC1. J Clin Oncol. 2006;24(18):2836-2841.

101. Geller SE, Shulman LP, van Breemen RB, et al. Safety and efficacy of black cohosh and red clover for the management of vasomotor symptoms: a randomized controlled trial. Menopause. 2009; 16(6):1156-1166.

102. Christy C. Vitamin E in menopause. Am J Obstet Gynecol. 1945; 50:84-87.

103. Finkler RS. The effect of vitamin E in menopause. J Clin Endo Metab. 1949;9:89-94.

104. Barton DL, Loprinzi CL, Quella SK, et al. Prospective evaluation of vitamin E for hot flashes in breast cancer survivors. J Clin Oncol. 1998;16(2):495-500.

105. Bardia A, Tleyjeh IM, Cerhan JR, et al. Efficacy of antioxidant supplementation in reducing primary cancer incidence and mortality: systematic review and meta-analysis. Mayo Clin Proc. 2008;83(1):23-34

106. Barton DL, Loprinzi C, Atherton PJ, et al. Dehydroepiandrosterone for the treatment of hot flashes: a pilot study. Support Cancer Ther. 2006;3(2):91-97.

107. Lasley BL, Santoro N, Randolf JF, et al. The relationship of circulating dehydroepiandrosterone, testosterone, and estradiol to stages of the menopausal transition and ethnicity. $J$ Clin Endocrinol Metab. 2002;87(8):3760-3767. 
108. Stomati M, Monteleone P, Casarosa E, et al. Six-month oral dehydroepiandrosterone supplementation in early and late postmenopause. Gynecol Endocrinol. 2000;14(5):342-363.

109. LowDog T. Menopause: a review of botanical dietary supplements. The American Journal of Medicine. 2005;118(12B):98S-108S.

110. Chenoy R, Hussain S, Tayob Y, O’Brien PM, Moss MY, Morse PF. Effect of oral gamolenic acid from evening primrose oil on menopausal flushing. BMJ. 1994;308(6927):501-503.

111. Hirata JD, Swiersz LM, Zell B, Small R, Ettinger B. Does dong quai have estrogenic effects in postmenopausal women? A double-blind, placebo-controlled trial. Fertil Steril. 1997;68(6):981-986.

112. Amato P, Christophe S, Mellon PL. Estrogenic activity of herbs commonly used as remedies for menopausal symptoms. Menopause. 2002;9(2):145-150.

113. Lau CB, Ho TC, Chan TW, Kim SC. Use of dong quai (Angelica sinensis) to treat peri- or postmenopausal symptoms in women with breast cancer: is it appropriate? Menopause. 2005;12(6):734-740.

114. Wiklund IK, Mattsson LA, Lindgren R, Limoni C. Effects of a standardized ginseng extract on quality of life and physiological parameters in symptomatic postmenopausal women: a double-blind, placebo-controlled trial. Swedish Alternative Medicine Group. Int $J$ Clin Pharmacol Res. 1999;19(3):89-99.

115. Lee J. Natural Progesterone: The Multiple Roles of a Remarkable Hormone. Sebastopol, CA: BLL Publishing; 1993.

116. Komesaroff PA, Black CV, Cable V, Sudhir K. Effects of wild yam extract on menopausal symptoms, lipids and sex hormones in healthy menopausal women. Climacteric. 2001;4(2):144-150.

117. The North American Menopause Society. Treatment of menopauseassociated vasomotor symptoms: position statement of The North American Menopause Society. Menopause. 2004;11(1):11-33.

118. Barton D, Loprinzi C, Wahner-Roedler D. Hot flashes: aetiology and management. Drugs Aging. 2001;18(8):597-606.

119. Daley A, MacArthur C, Mutrie N, Stokes-Lampard H. Exercise for vasomotor menopausal symptoms. Cochrane Database Syst Rev 2007(4):CD006108.

120. Daley AJ, Stokes-Lampard HJ, Macarthur C. Exercise to reduce vasomotor and other menopausal symptoms: a review. Maturitas. 2009;63(3):176-180.

121. Chattha R, Raghuram N, Venkatram P, Hongasandra NR. Treating the climacteric symptoms in Indian women with an integrated approach to yoga therapy: a randomized control study. Menopause. 2008;15(5):862-870.

122. Carson JW, Carson KM, Porter LS, Keefe FJ, Seewaldt VL. Yoga of Awareness program for menopausal symptoms in breast cancer survivors: results from a randomized trial. Support Care Cancer. 2009;17(10):1301-1309.

123. Lee MS, Kim JI, Ha JY, Boddy K, Ernst E. Yoga for menopausal symptoms: a systematic review. Menopause. 2009;16(3):602-608.

124. Freedman RR, Woodward S. Behavioral treatment of menopausal hot flushes: evaluation by ambulatory monitoring. Am J Obstet Gynecol. 1992;167(2):436-439.

125. Germaine LM, Freedman RR. Behavioral treatment of menopausal hot flashes: evaluation by objective methods. J Consult Clin Psychol. 1984;52(6):1072-1079.

126. Fenlon DR, Corner JL, Haviland JS. A randomized controlled trial of relaxation training to reduce hot flashes in women with primary breast cancer. J Pain Symptom Manage. 2008;35(4):397-405.
127. Kabat-Zinn J. Full Catastrope living: using the wisdom of your body and mind to face stress, pain, and illness. New York: Delacorte; 1990.

128. Carmody J, Crawford S, Churchill L. A pilot study of mindfulness-based stress reduction for hot flashes. Menopause. 2006;13(5):760-769.

129. Tremblay A, Sheeran L, Aranda SK. Psychoeducational interventions to alleviate hot flashes: a systematic review. Menopause. 2008; 15(1):193-202.

130. Stern JA, Brown M, Ulett GA, Sletten I. A comparison of hypnosis, acupuncture, morphine, valium, aspirin, and placebo in the management of experimentally induced pain. Ann NY Acad Sci. 1977; 296:175-193.

131. Wadden TA, Anderton CH. The clinical use of hypnosis. Psychol Bull. 1982;91(2):215-243.

132. Borkovec TD, Fowles DC. Controlled investigation of the effects of progressive and hypnotic relaxation on insomnia. J Abnorm Psychol. 1973;82(1):153-158.

133. Elkins GR. Consulting about insomnia: Hypnotherapy, sleep hygiene, and stimulus-control instructions. In: Matthews WJ, Edgette JH, editors. Current thinking and research in brief therapy. New York: Brunner/Mazel; 1997.

134. Gruber BL, Hersh SP, Hall NR, et al. Immunological responses of breast cancer patients to behavioral interventions. Biofeedback Self Regul. 1993;18(1):1-22.

135. Bridge LR, Benson P, Pietroni PC, Priest RG. Relaxation and imagery in the treatment of breast cancer. BMJ. 1988;297(6657):1169-1172.

136. Decker TW, Cline-Elsen J, Gallagher M. Relaxation therapy as an adjunct in radiation oncology. J Clin Psychol. 1992;48(3):388-393.

137. Elkins G, Marcus J, Stearns V, Hasan Rajab M. Pilot evaluation of hypnosis for the treatment of hot flashes in breast cancer survivors. Psychooncology. 2007;16(5):487-492.

138. Elkins G, Marcus J, Stearns V, et al. Randomized trial of a hypnosis intervention for treatment of hot flashes among breast cancer survivors. $J$ Clin Oncol. 2008;26(31):5022-5026.

139. Cho SH, Whang WW. Acupuncture for vasomotor menopausal symptoms: a systematic review. Menopause. 2009;16(5):1065-1073.

140. Lee MS, Kim KH, Choi SM, Ernst E. Acupuncture for treating hot flashes in breast cancer patients: a systematic review. Breast Cancer Res Treat. 2009;115(3):497-503.

141. Elias M. Cervical sympathetic and stellate ganglion blocks. Pain Physician. 2000;3(3):294-304.

142. Lipov E, Lipov S, Stark JT. Stellate ganglion blockade provides relief from menopausal hot flashes: a case report series. J Womens Health (Larchmt). 2005;14(8):737-741.

143. Lipov EG, Joshi JR, Sanders S, et al. Effects of stellate-ganglion block on hot flushes and night awakenings in survivors of breast cancer: a pilot study. Lancet Oncol. 2008;9(6):523-532.

144. Pachman DR, Barton D, Carns PE, et al. Pilot evaluation of a stellate ganglion block for the treatment of hot flashes. Submitted for publication. 2010.

145. Lipov EG, Lipov S, Joshi JR, Santucci VD, Slavin KV, Beck Vigue SG. Stellate ganglion block may relieve hot flashes by interrupting the sympathetic nervous system. Med Hypotheses. 2007;69(4):758-763
International Journal of Women's Health

\section{Publish your work in this journal}

The International Journal of Women's Health is an international, peerreviewed open-access journal publishing original research, reports, reviews and commentaries on all aspects of women's healthcare including gynecology, obstetrics, and breast cancer. Subject areas include: Chronic conditions (migraine headaches, arthritis, osteoporosis);

\section{Dovepress}

Endocrine and autoimmune syndromes; Sexual and reproductive health; Psychological and psychosocial conditions. The manuscript management system is completely online and includes a very quick and fair peer-review system. Visit http://www.dovepress.com/ testimonials.php to read real quotes from published authors. 